\title{
Cautious optimism and tempered enthusiasm for a more thorough, tailored intervention in ischemic moderate mitral regurgitation
}

\author{
John Bozinovski, MD, MSc
}

\author{
From the Division of Cardiac Surgery, University of British Columbia and the Royal Jubilee Hospital, Victoria, \\ British Columbia, Canada. \\ Disclosures: Author has nothing to disclose with regard to commercial support. \\ Received for publication May 19, 2018; revisions received May 19, 2018; accepted for publication May 21, 2018; \\ available ahead of print July 4, 2018. \\ Address for reprints: John Bozinovski, MD, MSc, 106-2020 Richmond Rd, Victoria, British Columbia, Canada \\ V8R-6R5 (E-mail: john.bozinovski@ubc.ca). \\ J Thorac Cardiovasc Surg 2018;156:1501-2 \\ $0022-5223 / \$ 36.00$ \\ Copyright $(\subset) 2018$ by The American Association for Thoracic Surgery \\ https://doi.org/10.1016/j.jtcvs.2018.05.073
}

Moderate mitral regurgitation (MR) in the setting of ischemic heart disease is not uncommon, particularly after a myocardial infarction (MI). ${ }^{1}$ It is more common after inferior MI when compared with anterior MI. ${ }^{2}$ When confronted with moderate MR, the decision to add a mitral valve intervention to a coronary artery bypass grafting (CABG) operation can be difficult. Many factors influence the choice of surgical strategy preferred by the patient and eventually pursued by the surgeon. Adding a mitral intervention prolongs surgical time and cardiac ischemic time $^{3-5}$ and, on occasion, requires a skill set that may not be mastered by the surgeon. The added mitral intervention may, ${ }^{3,4}$ or may not, ${ }^{5}$ increase complications. This risk is tempered by the benefit conferred by adding the mitral intervention, but this is equivocal. Although 3 randomized trials have shown no survival benefit with adding a restrictive mitral annuloplasty (RMA), ${ }^{4-6}$ ventricular remodeling and symptomatic improvements occurred in 2 of the studies $^{5,6}$ but not in the larger Cardiothoracic Surgical Trials Network study. ${ }^{4}$ So how do we proceed? Michler ${ }^{7}$ suggests assessing several qualitative and quantitative characteristics to guide the decision whether to repair moderate MR at the time of CABG.

Michler ${ }^{7}$ did well to explain the discrepant findings between the randomized trials of RMA in CABG, reasoning that the larger, presumably more scarred, ventricles of the earlier trials were better disposed to improvement with RMA and less likely to improve with CABG alone, since the nonviable myocardium will not improve with revascularization. The latter Cardiothoracic Surgical Trials Network trial had smaller left ventricular (LV) size, fewer incidences of MI, and presumably less-infarcted myocardium. As a result, these patients would more likely benefit from revascularization alone, attenuating any benefit RMA may confer. He proposes that patients with scar, LV dilatation, and suboptimal inferolateral target vessels valve intervention. moderate MR.

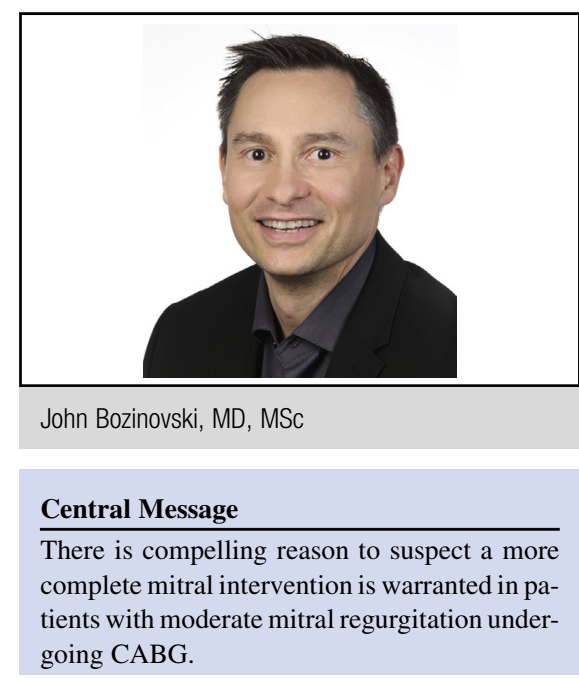

See Article page 1498 .

assessed using cardiac magnetic resonance, echocardiography, and cardiac catheterization, should undergo mitral

Michler ${ }^{7}$ argues that those patients with LV dilatation, especially in the face of a scarred ventricle, should be "considered" for a ventricular procedure such as a papillary muscle approximation (PMA) because PMA reduces LV end-systolic diameter and leaflet tethering and this reduction is sustained over time compared with RMA alone. ${ }^{8}$ His argument is logical, well-reasoned, and, since we haven't the evidence to support such, it is well-stated. In the aforementioned randomized trials, no leaflet, or subvalvular, work was required, but this still increased postoperative complications. Although RMA is straightforward, PMA is a more recently developed technique and one not mastered by many cardiac surgeons. PMA further adds to surgical and ischemic times and is another feature to be incorporated into the surgeon's decision algorithm when we as a community are still debating whether or, in whom, we should be adding an isolated RMA for ischemic moderate MR. Despite that, Dr Michler's ${ }^{7}$ argument is compelling and will find advocates who will hopefully perform the necessary investigations to determine the value of PMA in addition to RMA and CABG in ischemic 


\section{References}

1. Perez de Isla L, Zamorano J, Quezada M, Almeria C, Rodrigo JL, Serra V, et al. Functional mitral regurgitation after a first non-ST-segment elevation acute coronary syndrome: contribution to congestive heart failure. Eur Heart J. 2007;28:2866-72. 2. Kumanohoso T, Otsuji Y, Yoshifuku S, Matsukida K, Koriyama C, Kisanuki A, et al. Mechanism of higher incidence of ischemic mitral infarction: quantitative analysis of left ventricular and mitral valve geometry in 103 patients with prior myocardial infarction. J Thorac Cardiovasc Surg. 2003;125:135-43.

3. Herlitz J, Brandrup-Wognsen G, Caidahl K, Haglid M, Karlsson BW, Karlsson T, et al. Mortality and morbidity among patients who undergo combined valve and coronary artery bypass surgery: early and late results. Eur J Cardiothorac Surg. 1997; 12:836-46.

4. Smith PK, Puskas JD, Ascheim DD, Voisine P, Gelijns AC, Moskowitz AJ, et al; for the Cardiothoracic Surgical Trials Network Investigators. Surgical treatment of moderate ischemic mitral regurgitation. N Engl J Med. 2014;371:2178-88.
5. Chan KMJ, Punjabi PP, Flather M, Wage R, Symmonds K, Roussin I, et al. Coronary artery bypass surgery with or without mitral valve annuloplasty in moderate functional ischemic mitral regurgitation: final results of the randomized ischemic mitral evaluation (RIME) trial. Circulation. 2012;126: 2502-10.

6. Fattouch K, Guccione F, Sampognaro R, Panzarella G, Corrado E, Navarra E, et al. Efficacy of adding mitral valve restrictive annuloplasty to coronary artery bypass grafting in patients with moderate ischemic mitral valve regurgitation: a randomized trial. J Thorac Cardiovasc Surg. 2009;138:278-85.

7. Michler RE. Surgical management of moderate ischemic mitral regurgitation at the time of coronary artery bypass grafting remains controversial. J Thorac Cardiovasc Surg. 2018;156:1498-500.

8. Nappi F, Lusini M, Spadaccio C, Nenna A, Covino E, Acar C, et al. Papillary muscle approximation versus restrictive annuloplasty alone for severe ischemic mitral regurgitation. J Am Coll Cardiol. 2016;24:2334-46. 